\title{
Sistem Informasi Pengolahan Data Laporan Arus Kas Berbasis Website Pada CV Sari Agung Perkasa (SAP) Ternate
}

\author{
Infanti Rusdi \\ Program Studi Manajemen Informatika \\ Politeknik Sains dan Teknologi Wiratama Maluku Utara \\ infanti03_rusdi@gmail.com
}

\begin{abstract}
Abstrak
CV Sari agung perkasa merupakan salah satu badan usaha yang mempunyai cabang perusahaannya di kota ternate yang bergerak dalam bidang penjualan karya seni (kaligrafi), system pengolahan data laporan kas pada CV sari agung tersebut masih bersifat konvesional, yaitu pencatatan data penerimaan dan pengeluaran masih di lakukan secara manual dan proses penyampaian pelaporanpun yang di berikan kepada pimpinan perusahaan, harus mengirim pelaporan tersebut ke pimpinan perusahaan yang berada di luar kota ternate, sehingga dianggap kurang efektif dan efisien. Penilitian ini dilakukan pada CV Sari Agung Perkasa Cabang (SAP) Ternate bertujuan untuk merancang suatu aplikasi untuk mengolah data kas penerimaan dan pengeluaran berbasis website, metode pengumpulan data menggunakan observasi, wawancara. Model pengembangan sistem yang digunakan model waterfall dengan pendekatan rancangan diagram flow data (DFD), bahasa pemrograman yang digunakan PHP dan MySql sebagai Databasenya dan model pengujian sistem menggunakan metode Blackbox. Dengan adanya sistem ini diharapkan dapat mempermudah dalam mengelola data kas serat mempermudah prose penyampaian laporan kepada pimpinan yang berada diluar kota ternate
\end{abstract}

\section{Kata kunci: Sistem Informasi, Arus Kas, Website}

\section{Abstract}

$C V$ Sari agung perkasa is one of the business entities that have branches of his company in the town of ternate who engaged in the sale of works of art (calligraphy), cash report data processing system on CV sari agung is still conventional, namely the recording of data cash receipts and cash outlay are still done manually and the report submission process was given to the head of the company must send the report to the head of the company which is outside the ternate city so it is considered less effective and efficient. This research was conducted at CV Sari Agung Perkasa Branch (SAP) Ternate aims to design an application to process cash receipts and expenditure-based website. method of data collection using observation, interview. System development model used waterfall model with design flow diagram data (DFD), programming language used PHP and MySql as database and system testing model using Blackbox method. With this system is expected to facilitate in managing the fiber cash data facilitate the process of report submission to leaders who are outside the city ternate.

Keywords: Information Systems, CashFlow, Website

\section{PENDAHULUAN}

Dalam era globalisasi dan teknologi dewasa ini, penggunaan komputer sebagai salah satu alat teknologi informasi sangat dibutuhkan keberadaannya hampir disetiap aspek kehidupan. Penggunaan perangkat komputer sebagai perangkat pendukung manajemen dan pengolahan data adalah sangat tepat dengan mempertimbangkan kuantitas dan kualitas data, dengan demikian penggunaan perangkat komputer dalam setiap informasi sangat mendukung sistem pengambilan keputusan. Sejalan dengan 
cepatnya perkembangan dalam teknologi informasi maka setiap badan usaha semakin dipacu untuk menggunakan teknologi maju sebagai salah satu alat untuk menghasilkan kinerja yang lebih efektif dan efisien.

Penjualan merupakan salah satu fungsi pemasaran yang sangat penting dan menentukan bagi perusahaan dalam mencapai tujuan perusahaan, memperoleh laba untuk kelangsungan hidup perusahaan. Sistem yang baik sangatlah dibutuhkan oleh perusahaan demi Meningkatkan kemajuan perusahaan itu sendiri dan menghindari terjadinya berbagai masalah baik didalam maupun luar perusahaan. Kas merupakan aktiva paling liquid, dimana dapat dipakai sebagai alat pembayaran yang siap dan bebas dipergunakan untuk membiayai kegiatan umum perusahaan. Sehingga kas disajikan pada urutan pertama dari aktiva. Menurut Mulyadi (2008) sumber penerimaan kas terbesar suatu perusahaan dagang adalah berasal dari transaksi penjualan tunai

Sari agung perkasa merupakan salah satu badan usaha yang mempunyai cabang perusahaannya di kota ternate yang bergerak dalam bidang penjualan karya seni (kaligrafi), pada Sari Agung cabang kota ternate system pengolahan data laporan kas masih bersifat konvesional, yaitu pencatatan data penerimaan dan pengeluaran masih di lakukan secara manual dan proses penyampaian pelaporanpun yang di berikan kepada pimpinan perusahaan, harus mengirim pelaporan tersebut ke pimpinan perusahaan yang berada di luar kota ternate, sehingga dianggap kurang efektif dan efisien

Berdasarkan uraian latar belakang maka dibutuhkan satu sistem yang terkomputerisasi yang berbasis website agar dapat menunjang kegiatan dalam mengelola data penjualan mengirim data laporan dimana saja pada sistem

\section{Rumusan Masalah}

1. Sari Agung cabang kota ternate system pengolahan data laporan kas masih bersifat konvesional, yaitu pencatatan data laporan penerimaan dan pengeluaran masih di lakukan secara manual

2. karyawan tersebut harus mengirim laporan kas ke pimpinan perusahaan yang berada diluar daerah sehingga kurang efektif dan efisien

berdasarkan pokok masalah diatas maka dapat dirumuskan masalah adalah bagaiamana merancang sistem informasi pengolahan data laporan arus kas berbasis web pada CV Agung Perkasa Cabang Ternate

\section{Tujuan Penelitian}

Merancang suatu aplikasi untuk mengolah data kas penerimaan dan pengeluaran berbasis website sehingga Mempermudah karyawan dalam mengelola data kas serta mempermudah dalam proses pengiriman laporan tersebut

\section{Manfaat Penelitian}

\begin{tabular}{l}
\multicolumn{1}{c}{ Dapat Meningkatkan kinerja } \\
perusahaan terutama dalam dalam \\
pelayanan dan pengolahan data kas \\
terutama pada penermaan dan pengeluaran \\
serta proses pengiriman laporan tersebut
\end{tabular}

\section{Tinjauan Pustaka}

Penelitian yang dilakukan Syaprina Leon Andretti Abdillah, \& Nyimas Sopiah (2008) yang berjudul Sistem Informasi Penjualan Dan Perbaikan Komputer (Studi Kasus: CV. Computer Plus Palembang) 
tujuan penelitian Diharapkan Dapat mempermudah dalam mengelola data transaksi penjualan dan perbaikan computer Pembuatan laporan penjualan dan perbaikan computer serta mempermudah dalam pengecekan persediaan barang yang berada digudang, hasil dari penelitian system informasi penjualan dan perbaikan computer pada CV. Computer Plus Palembang Memberikan kemudahan pada bagian administrasi dalam mengolah data penjualan dan perbaikan computer pada CV. Computer Plus Palembang, serta dapat memudahkan dalam mengecek persediaan barang pada gudang.

Penelitian yang dilakukan oleh Sofian Horas H Siregar, 2010 tentang Sistem Informasi Pembelian, penjualan dan persediaan pada Rudi Agency bertujuan Mengatasi masalah efesiensi dan ketepatan penggunaan waktu dalam memproses laporan. Pembelian, Penjualan dan Persediaan. Dari Penelitian ini Menghasilkan laporan pembelian (per tanggal per supplier, per tanggal per customer, per produk) dan laporan persediaan dalam waktu yang relative singkat sesuai dengan kebutuhan pemilik proses pengecekan dan maupun pencarian data dilakukan dengan cepat dan mudah

Berdasarkan kedua uraian peniltian diatas maka perbandingan dengan peniltian ini adalah pada peniltian ini menggunakan bahasa pemrograman php dan MySql sebagai databasenya sedangkan penelitian diatas masing-masing mengelola data transaksi dengan menggunakan bahasa pemrograman visual

\section{LANDASAN TEORI}

\section{Pengertian Sistem}

Secara umum,sistem dapat diartikan sebagai suatu kesatuan yang terdiri dari dua atau lebih komponen-komponen yang saling berinteraksi untuk mencapai tujuan (Mukhtar,2010).

Jogiyanto (2008) juga mengemukakan definisi sistem yaitu kumpulan dari elemen-elemen yang berinteraksi untuk mencapai suatu tujuan tertentu,yang artinya saling bekerjasama dalam membentuk satu kesatuan untuk melakukan suatu kegiatan/menyelesaikan suatu sasaran tertentu

\section{Pengertian Informasi}

Informasi adalah data yang diolah menjadi bentuk yang lebih berguna dan lebih berarti bagi penerimanya (Jogiyanto,2008). Informasi merupakan hasil pengolahan dari sebuah model, formasi, organisasi, atau sebuah perubahan bentuk dari data yang memiliki nilai tertentu dan bisa digunakan untuk menambah pengetahuan bagi yang menerimanya

\section{Pengertian Sistem Informasi}

Jogiyanto (2008) mengemukakan bahwa sistem informasi adalah sekumpulan komponen pembentuk sistem yang mempunyai keterkaitan antara satu komponan dengan komponen lainnya yang bertujuan menghasilkan suatu informasi dan suatu bidang tertentu. Dalam sistem informasi diperlukannya klasifikasi alur informasi oleh pengguna informasi. Kriteria dari system informasi antara lain, fleksibel, efektif, dan efesien

\section{Perancangan Sistem}

Perancangan sistem adalah merancang atau mendesain sistem yang baik,isinya adalah langkah-langkah operasi dalam pengolahan data dan prosedur untuk mendukung operasi sistem. Dalam perancangan sistem diperlukan beberapa alat bantu. Adapun alat bantu yang 
digunakan dalam perancangan sistem Context Diagram (CD), Data Flow Diagram (DFD), dan Flowchart

\section{Pengertian MySQL}

Menurut Hirin dan Virgi (2011), MySQL adalah salah satu perangkat lunak sistem manajemen basis data (database) SQL atau sering disebut dengan DBMS (Database Management System)

\section{Web Server Apache}

Web server Apache open source dan mulai populer di internet sejak tahun 1996 karena Open Source. Apache bebas didistribusikan oleh siapa saja dan kesiapa saja. Menurut Bunafit Nugroho,2007:17). Tugas utama Apache adalah menghasilkan halaman web yang benar kepada user berdasarkan kode PHP yang dituliskan oleh pembuat halaman web. Jika diperlukan, berdasarkan kode PHP yang dituliskan maka dapat saja suatu database diakses terlebih dahulu (misalnya dalam MySQL) untuk mendukung halaman web yang dihasilkan. Pengertian database adalah sekumpulan data yang sudah disusun sedemikan rupa dengan ketentuan atau aturan tertentu yang saling berelasi sehingga memudahkan pengguna dalam mengelolanya juga memudahkan memperoleh informasi

\section{Penerimaan Kas}

Menurut Soemarso (2004:172): "Peneriamaan kas adalah suatu transaksi yang menimbulkan bertumbuhnya saldo kas dan bank milik perusahaan yang diakibatkan adanya penjualan hasil produksi, penerimaan piutang maupun hasil transaksi lainnya yang menyebabkan bertambahnya kas."

\section{Pengertian Pengeluaran Kas}

Pengeluaran kas merupakan suatu transaksi yang sering terjadi. Menurut Mulyadi (2008:543), pengeluaran kas adalah suatu catatan yang dibuat untuk melaksanakan kegiatan pengeluaran baik dengan cek maupun dengan uang tunai yang digunakan untuk kegiatan umum perusahaan.

Menurut Soemarso S.R (2009:297), Pengeluaran kas adalah suatu transaksi yang menimbulkan berkurangnya saldo kas dan bank milik perusahaan yang diakibatkan adanya pembelian tunai, pembayaran utang maupun hasil transaksi yang menyebabkan berkurangnya kas

\section{Pengertian Jurnal Akuntansi}

Jurnal merupakan catatan akuntansi pertama yang digunakan untuk mencatat, mengklasifikasikan, dan meringkas data keuangan dan data lainnya (Mulyadi, 2008;4). Dalam jurnal ini data keuangan untuk pertama kalinya diklasifikasikan menurut penggolongan yang sesuai dengan informasi yang akan disajikan dalam laporan keuangan

\section{METODE PENELITIAN Metode Pengumpulan Data}

Metode pengumpulan data yang di gunakan dalam penelitian ini adalah observasi dan wawancara

\section{Metode Pengembangan Sistem}

Metode air terjun atau yang sering disebut metode waterfall sering dinamakan siklus hidup klasik (classic life cycle), dimana hal ini menggambarkan pendekatan yang sistematis dan juga berurutan pada pengembangan perangkat lunak, dimulai dengan spesifikasi kebutuhan pengguna lalu berlanjut melalui tahapan-tahapan perencanaan (planning), permodelan (modeling), konstruksi 
(construction), serta penyerahan sistem ke para pelanggan/pengguna (deployment)

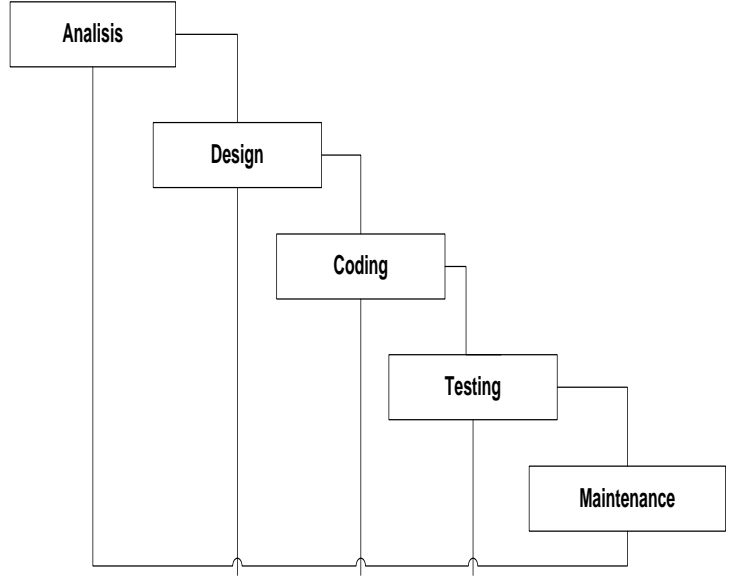

Gambar 1. Model Waterfall

\section{Kerangka Berpikir}

Kerangka berpikir merupakan urutan langkah yang dilakukan penelitian dalam memulai penelitian berdasarkan metode yang diikuti, berikut merupakan gambar alur kerangka berpikir

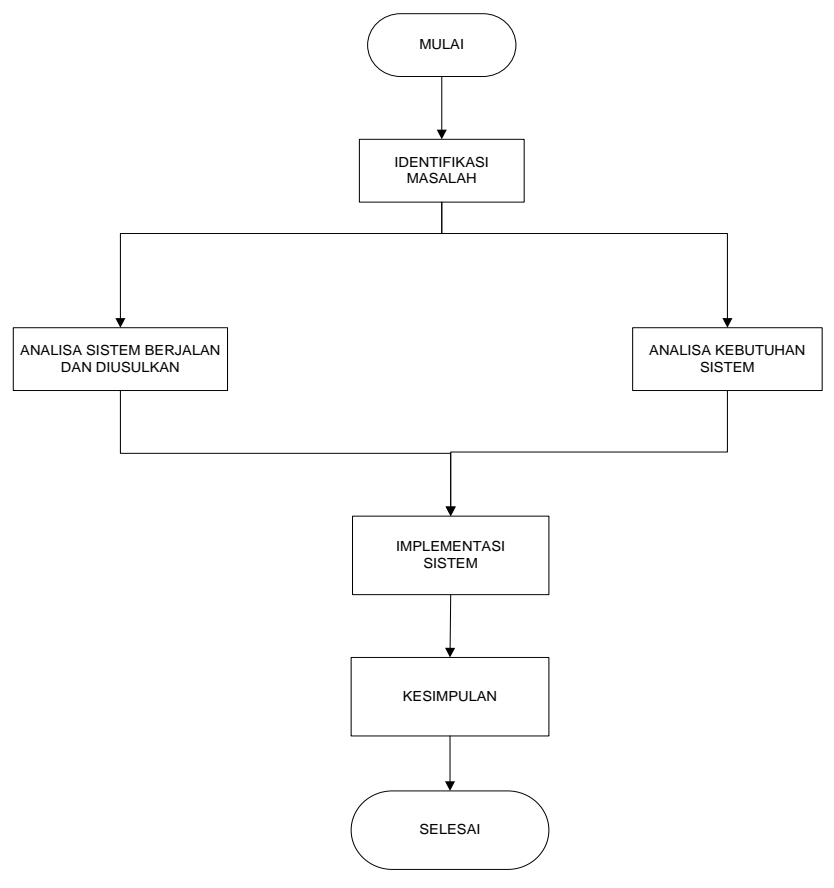

Gambar 2. Kerangka Pikir

ANALISIS DAN PERANCANGAN

Analsis Sistem yang berjalan

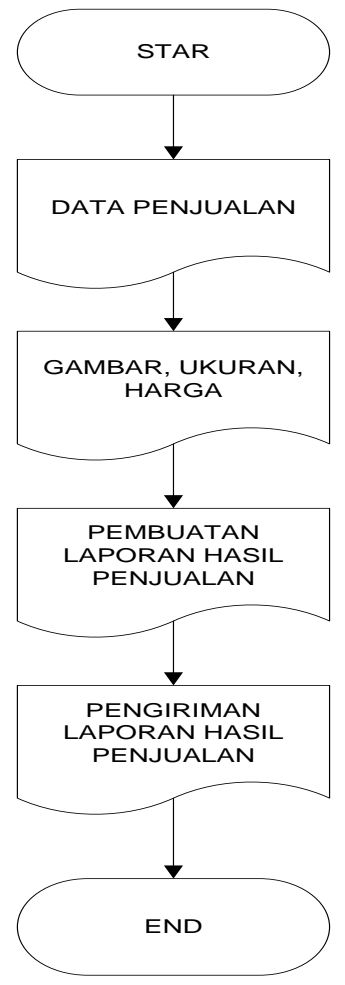

Gambar 3. Analisis Sistem berjalan

\section{Analsis Sistem yang diusulkan}

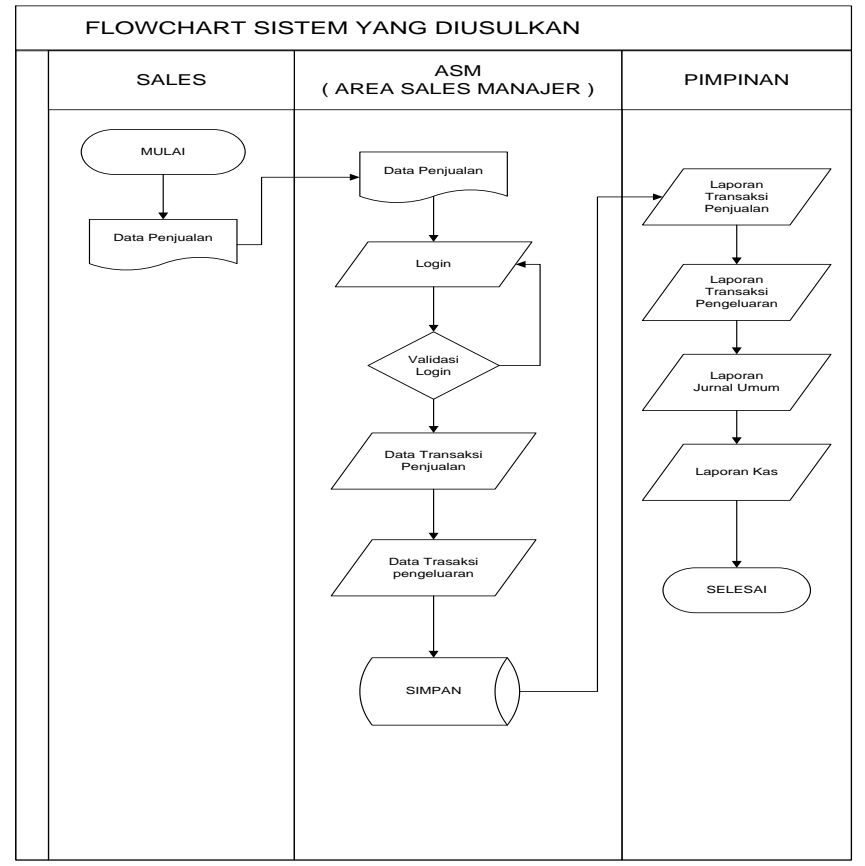

Gambar 4. Analisis Sistem diusulkan Diagram Konteks 


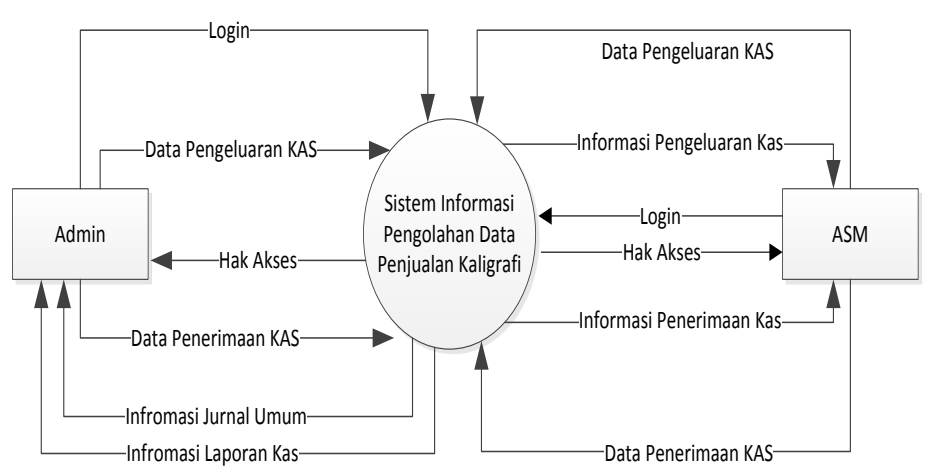

Gambar 5. Diagram Konteks

\section{Data Flow Diagram Level 1}

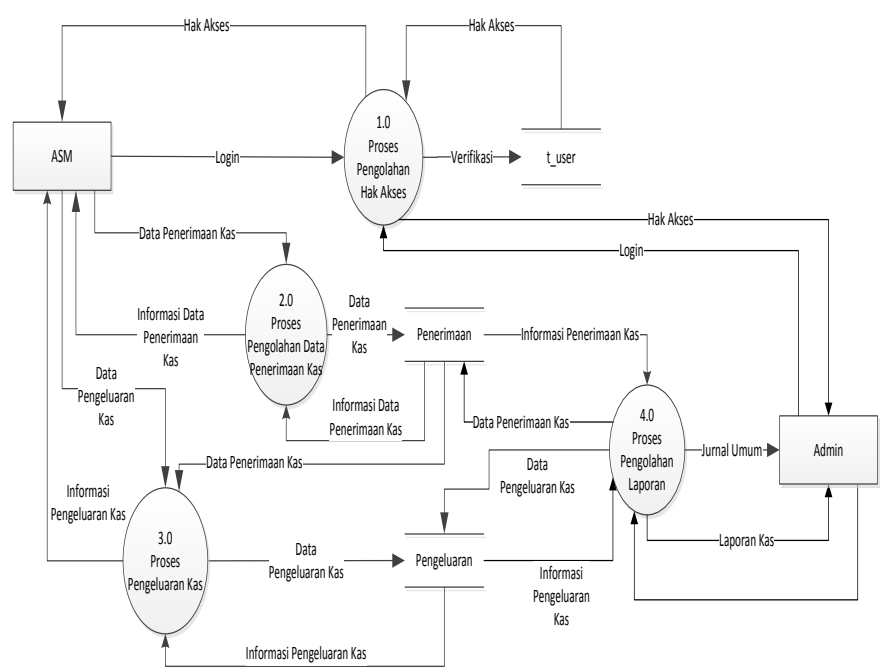

Gambar 6. DFD Level 1

\section{Rancangan Tabel}

Tabel 1. Tabel Penerimaan

\begin{tabular}{|l|l|c|}
\hline Nama Field & \multicolumn{1}{c|}{ Type Data } & Ket \\
\hline Idp & int(10) & AutoInc \\
\hline Kasid & int(10) & Index \\
\hline Tgl & Date/Time & \\
\hline Uraian & varchar(50) & \\
\hline Jumlah & int(10) & \\
\hline
\end{tabular}

Tabel 2. Tabel Pengeluaran

\begin{tabular}{|l|l|c|}
\hline Nama Field & \multicolumn{1}{|c|}{ Type Data } & Ket \\
\hline Kid & Int(10) & AutoInc \\
\hline Kasid & Int(10) & Index \\
\hline Idk & Int (10) & \\
\hline Tgl & Date/Time & \\
\hline Uraian & varchar(50) & \\
\hline Jumlah & Interface(10) & \\
\hline
\end{tabular}

Tabel 3. Tabel User

\begin{tabular}{|l|l|c|}
\hline Nama Field & \multicolumn{1}{|c|}{ Type Data } & Ket \\
\hline id_user & int(100) & AutoInc \\
\hline nama & varchar(50) & \\
\hline username & varchar(20) & \\
\hline password & varchar(100) & \\
\hline akses & varchar(10) & \\
\hline
\end{tabular}

\section{ERD}

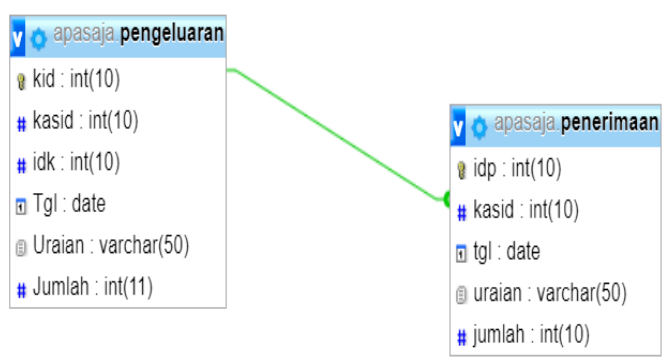

Gambar 7. ERD

\section{Rancangan User Interface}

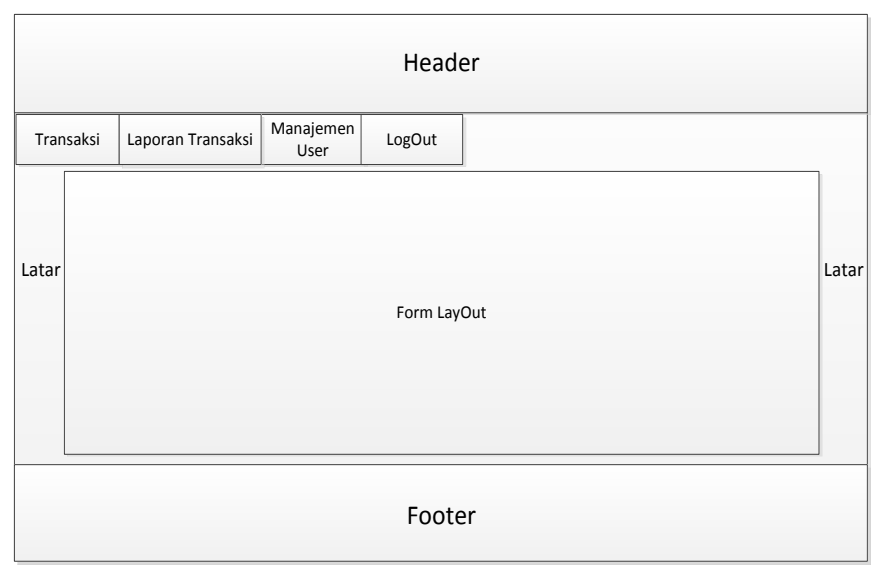

Gambar 8. Rancangan layout menu

\section{IMPLEMENTASI DAN PEMBAHASAN}

Form Menu utama

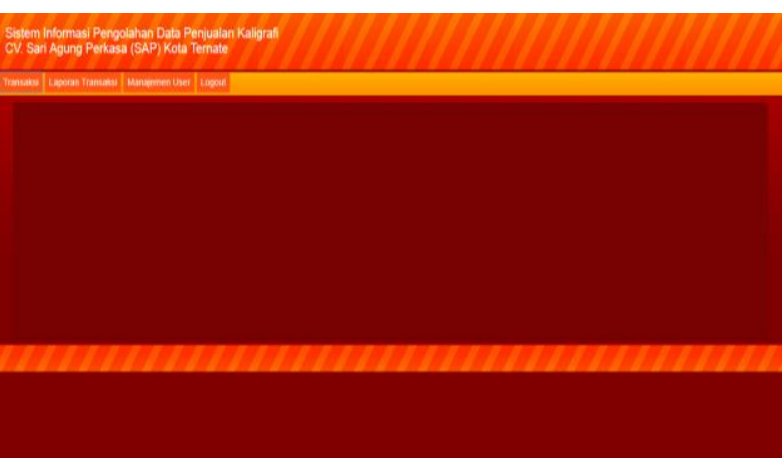

Gambar 9. Form menu utama

\begin{tabular}{|l|l|l|}
\hline Nama Field & Type Data & Ket \\
\hline
\end{tabular}


Form Transaksi Penerimaan

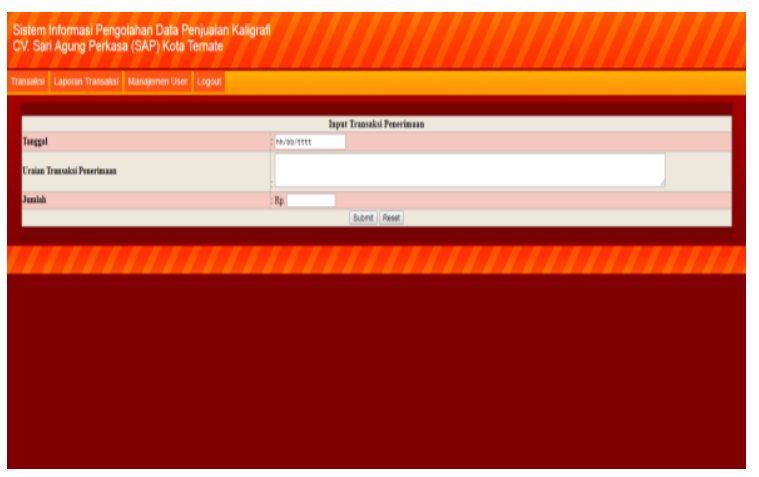

Gambar 10. Form transaksi penerimaan

\section{Form Lihat Transaksi Penerimaan}

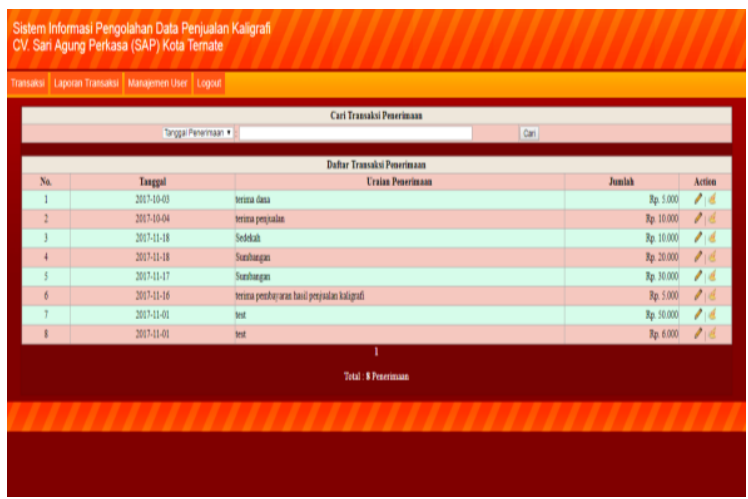

Gambar 11. Form lihat transaksi

\section{Form Transaksi Pengeluaran}

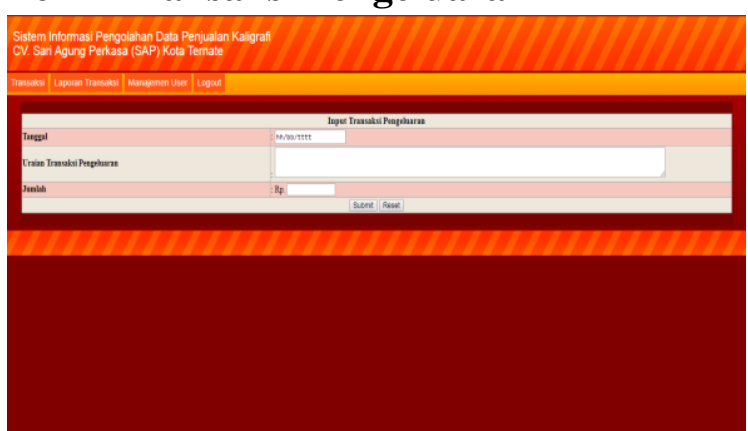

Gambar 12. Form Pengeluaran

\section{Form Lihat Pengeluaran}

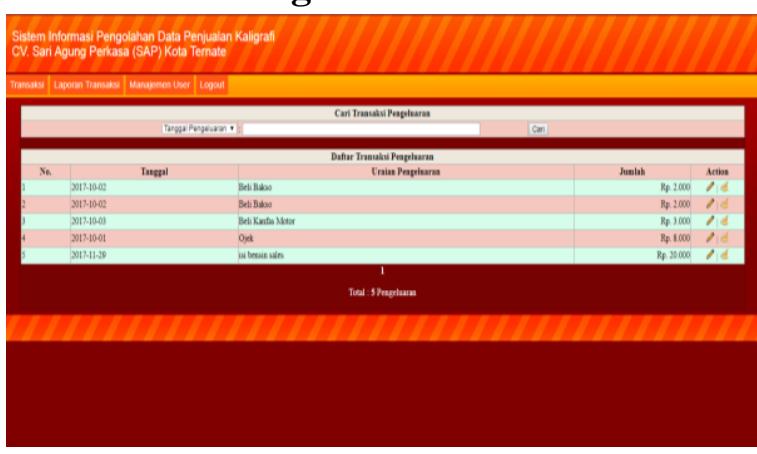

Gambar 13. Form Lihat Pengeluaran
Form Laporan Transaksi Penerimaan

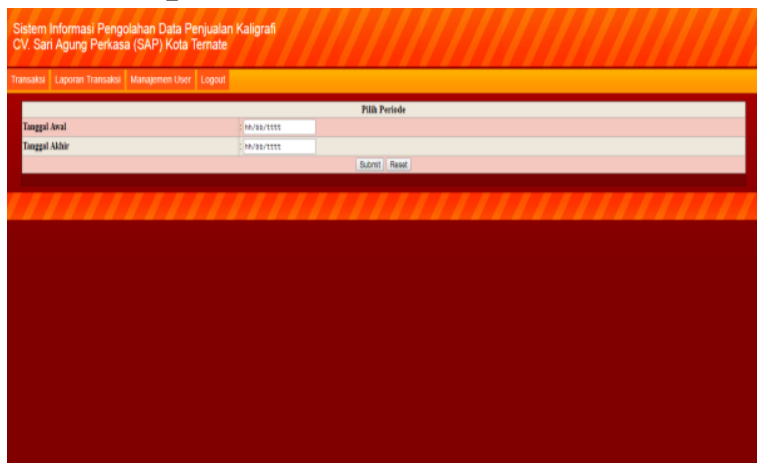

Gambar 14. Form Laporan Penerimaan

\section{Form Laporan Transaksi Pengeluaran}

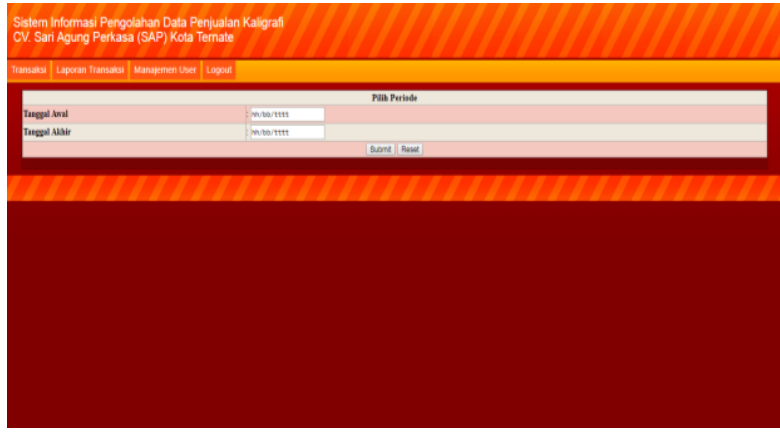

Gambar 15. Form Laporan Pegeluaran

\section{Form Jurnal Umum}

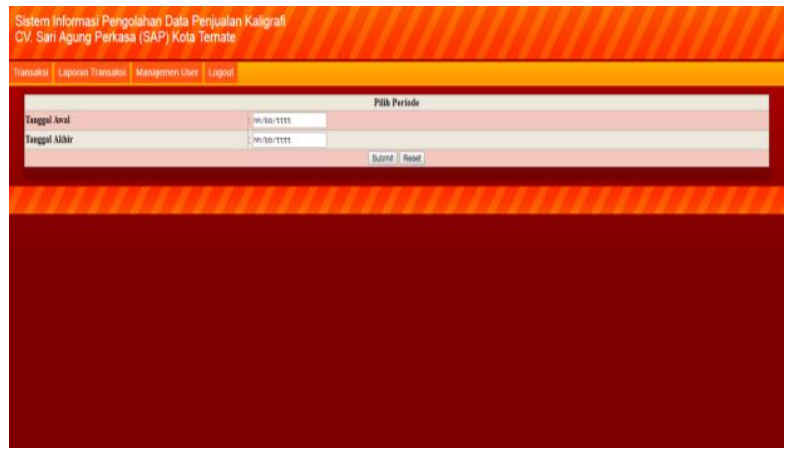

Gambar 16. Form Jurnal Umum

\section{Form manajemen Input User}

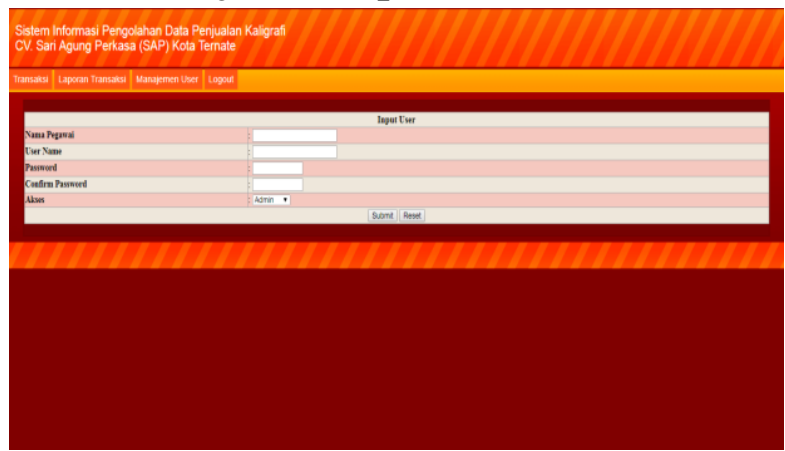

Gambar 17. Form Input User 
Form Manajemen Lihat User

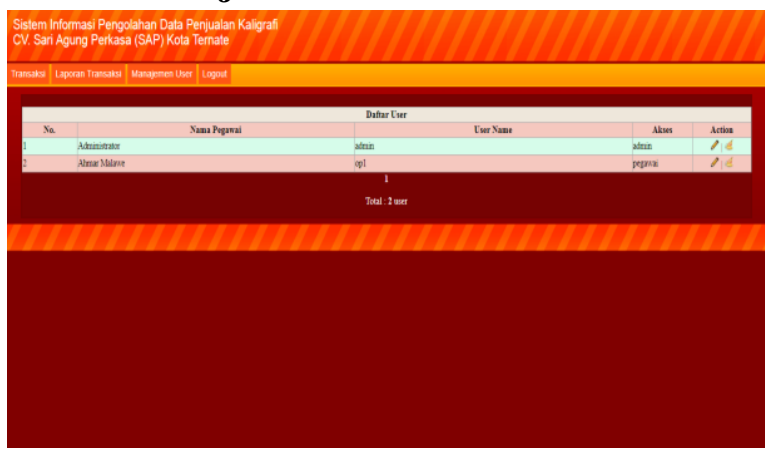

Gambar 18. Form Input User

\section{Form Cetak Laporan Penerimaan dan Pengeluaran}
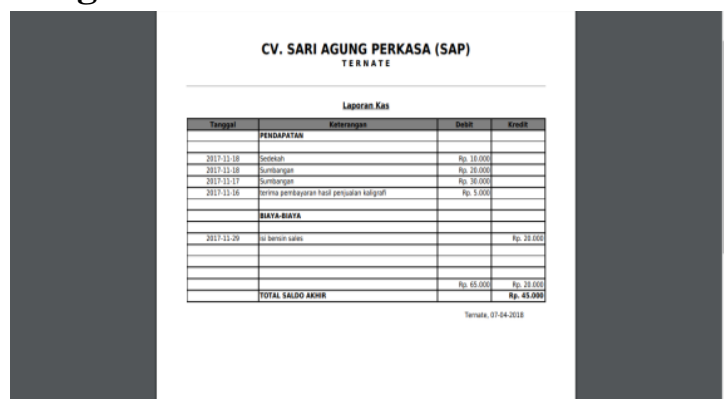

Gambar 19. Form cetak laporan

\section{Pengujian Sistem}

Menurut Rizky dalam penelitian Nina Rahayu (2014), Black Box Testing adalah tipe testing yang memperlakukan perangkat lunak yang tidak diketahui kinerja internalnya. Sehingga para tester memandang perangkat lunak seperti layaknya sebuah "kotak hitam" yang tidak penting dilihat isinya, tapi cukup dikenai proses testing di bagian luar

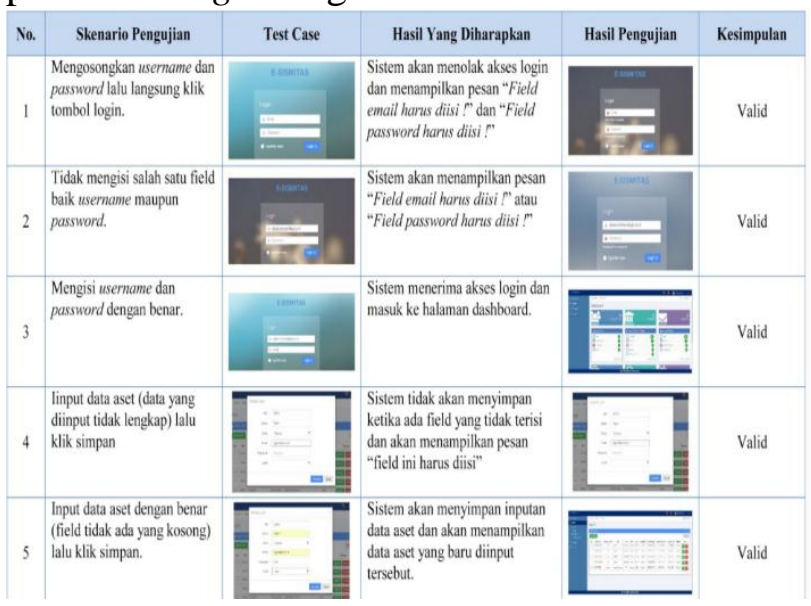

Gambar 20. Kolom Pengujian Sistem

\section{KESIMPULAN}

Berdasarkan hasil implementasi dan pengujian sistem maka disimpulkan bahwa

1. sistem ini dapat mempermudah pegawai atau karyawan pada $\mathrm{CV}$ Sari Agung dalam mengelola data kas secara komputerisasi dengan mengunakan website

2. sistem ini mempermudah penyampaian laporan penerimaan dan pengeluaran ke pimpinan yang berada diluar kota ternate

\section{Saran}

Berdasarkan kesimpulan maka dapat disarankan untuk pengembangan dan penelitian berikut

1. Agar dalam mengelola sistem tersebut diperlukan pelatihan kepada user yang menggunakan sistem ini nantinya agar lebih maksimal

2. Ke depan sistem dikembangkan dengan tampilan form dan model desain warna yang menarik

\section{DAFTAR PUSTAKA}

Lamport, L., 1994, LaTeX: A Document Preparation System, Second Edition, Addison Wiley, Canada

Utami, E., 2010, JawaTeX Web: Web Based Latin to Javanese Characters Transliteration System, International Journal of Computer Science \& Emerging Technologies (IJCSET), ISSN: 2044-6004, Vol. 1 Issue.1 June, 2010

Fathansyah. 2012. Basis Data. Bandung: Informatika.

Hidayahtullah, P., dan Kawistara, J, K., 2014. Pemograman Web. Bandung: Informatika

Mulyadi. 2008. Sistem Akuntansi. Jakarta: Salemba Empat

Jayan. 2010. CSS Untuk Orang Awam (membangun website tanpa tabel, 
fleksibel dan efektif). Palembang: Maxikom.

Jogiyanto, H. M., 2013. Sistem Teknologi Informasi Bisnis Pendekatan Stategis. Jakarta: Salembat Empat Jogiyanto 2008. Metodologi Penelitian Sistem Informasi. Yogyakarta CV. Andi Offset.

Syaprina, Abdillah, Leon. H., dan Sopiah, Nyimas. 2008. Sistem Informasi Penjualan Dan Perbaikan Komputer (Studi Kasus: CV. Computer Plus Palembang). Jurnal Ilmiah Matrik, Vol 10, No 2.

Sofian Horas H Siregar, 2010, Sistem Informasi Pembelian, penjualan dan persediaan pada Rudi Agency, Ejournal.narotama.ac.id

Daniel Bunga Pailin, 2012, Perancangan Sistem Informasi Penjualan pada Toko Ribo Jaya Ambon, Jurnal ARIKA berISSN, Vol. 06, No. 1, 2012

Rahayu, Nina. 2014. Perancangan Executive Informasion System (EIS) Dalam Bidang Penjualan Pada Karinda Café dan Resto. Skripsi. Tangerang: STMIK Raharja.

Soemarso S. R. 2004. "Akuntansi Suatu Pengantar". Buku satu. Edisi lima. Jakata: Salemba Empat 